\title{
Green Computing: A Case Study of Rajarshi Shahu Mahavidyalaya, Latur, INDIA
}

\author{
J. V. Mashalkar \\ S.R.T.M.University \\ Nanded (MS) \\ R.S.College Latur \\ Maharashtra
}

\author{
S. K. Kasbe \\ S.R.T.M.University \\ Nanded(MS) \\ R.S.College Latur \\ Maharashtra
}

\author{
M. B. Bhatade \\ S.R.T.M.University \\ Nanded(MS) \\ R.S.College Latur \\ Maharashtra
}

\begin{abstract}
College campuses and universities can use the concept of green computing very efficiently. The paper aims to assess awareness levels of IT users with regards to Green Computing; that is using IT in ways that are not harmful to the environment. A recommendation will be given on how Green Computing strategies can be implemented at RS College. Green computing is the study and practice of efficient and eco-friendly computing resources. Some common green computing practices include turning of the monitor when its not in use or using more energy efficient monitors like liquid crystal diode (LCD) instead of the traditional cathode ray tube (CRT) monitors. The objective of this paper is saving electricity consumption in computer science and information technology of RS College Latur In Case Of LCD and CRT monitors. This paper gives a description about laboratories of department of computer science and IT. Also, the paper explains the need of Green Computing at department of computer science and IT .The conclusion of the case study illustrates the saving in electricity by using some methods like payback period. Statistics were sought to establish the levels of awareness of negative impacts of IT and of environmental sustainability awareness or green computing.
\end{abstract}

KEYWORDS- RS College, Green Computing, electricity consumption

\section{INTRODUCTION}

"Green Computing is the practice of using computer resources efficiently [1]. Another definition is the one which defines green computing as the study and practice of efficient and eco-friendly computing resources. Green computing is no longer viewed as an issue of environmental organizations alone but other businesses such as commercial, universities, governments etc. have started paying attention to it as well [2].

Green computing is:

- the environmentally responsible use of computers and related resources.

- the use of energy efficient technologies, techniques and devices aimed at helping the environment.

- also referred to as Green IT

The primary goals of green computing are:

- to reduce the use of hazardous materials

- to maximize the energy efficiency during the product's lifetime
- to promote biodegradability or recycle ability of defunct products and factory waste[3].

Green computing is concerned with reducing the environmental impact of (Information Technology) IT before IT devices are pur-chased, during their lifetimes and after we have finished with them. Most manufacturers are improving their processes at the different levels of the product life to lessen harm as they are using the materials which are usually ecofriendly, renewable or might use less energy [4].Various Colleges and universities are implementing the following strategies to reduce environmental impact of computers during their use; when IT devices are not in use they are put in sleep mode, IT machines are switched off when not in use, sharing documents and files on the screen or use FTP servers and only print on demand and where necessary, using virtualization software instead of physical machines/servers, printing less etc. The product lives of product must be prolonged through upgrade options rather than finishing the lifespan of products. Old IT products can be donated to charities and refurbishing organizations which might increase the product life [3]. The above are some of the strides made in ensuring green computing for sustainable environment. This paper is concerned with conducting a research on electricity consumption of department of computer science and IT in RS College.

\section{NEED OF GREEN COMPUTING AT RSML}

Out of these areas, our CS and IT department of RS college is concentrated on electricity consumption .The focus of this paper is to reduce the electricity consumption in RS college .In this department what should be noted is that students and staff at department of CS and IT spend an average of nine hours a day on computers, either doing their assignments and doing practicals or doing their work everyday. What is evident is that the use of computers is growing at a phe-nomenal rate and naturally so is the consumption of electricity. A computer is made up of many components that consume power: the CPU, hard drives, graphic cards, monitors, speakers, printers, communication devices, scanners, etc. "Ref. [6]"state that; the average desktop computer consumes about 120 watts of electricity, on average, the monitor consumes 75 watts, and the CPU consumes 45 watts, laptops consumes between 15 and 45 watts. There are around 103 desktop computers at RS College and if they are all left on all the time they would consume a total of 1,366 megawatts-hours per year. 
During their operations computers not only consume energy but also leave carbon foot prints. IT-related equivalent carbon dioxide $(\mathrm{CO} 2 \mathrm{e})$ emissions alone have been estimated at two per cent of the world's total [3].

What prompted this research paper is the fact that, at face value, students and other computer users are oblivious to the negative impacts of computers. As stated earlier this research will attempt to establish how much RS College community has incorporated green policy strategies into their operations.

\section{RESEARCH PROBLEMS}

\subsection{Electricity Consumption}

Energy Conservation and Strategies and Practices Users must be encouraged to implement power management options on their machines.

$\square$ Reducing the overall time the system as a whole and monitor is on.

Ensuring that peripherals that are not in use are switched off as well as switching off air conditioners and lights that are not in use.

Improve electrical metering practices in order to enable the development of an energy consumption measurement program and energy indicators that break down energy consumption in a way that is easily communicable and relevant to the campus.

Fig. 2 below shows comparative results of a study that was done to show the power consumption (in watts) of 20" Dell LCD monitors at different states [7].

Note that from Fig. 2; when unplugged the monitor does not use any energy, but when it is off it can still use some bit of energy. In sleep mode it will use more energy than when it is off. Observe how, the study revealed elevated consumption of energy when the monitor is on [7].

Figure (1) below shows the desktop and laptop power consumption (in watts). Please note the differences in power consumptions for unplugged, off, sleep mode, $\mathrm{ON}, \quad$ hibernate mode.

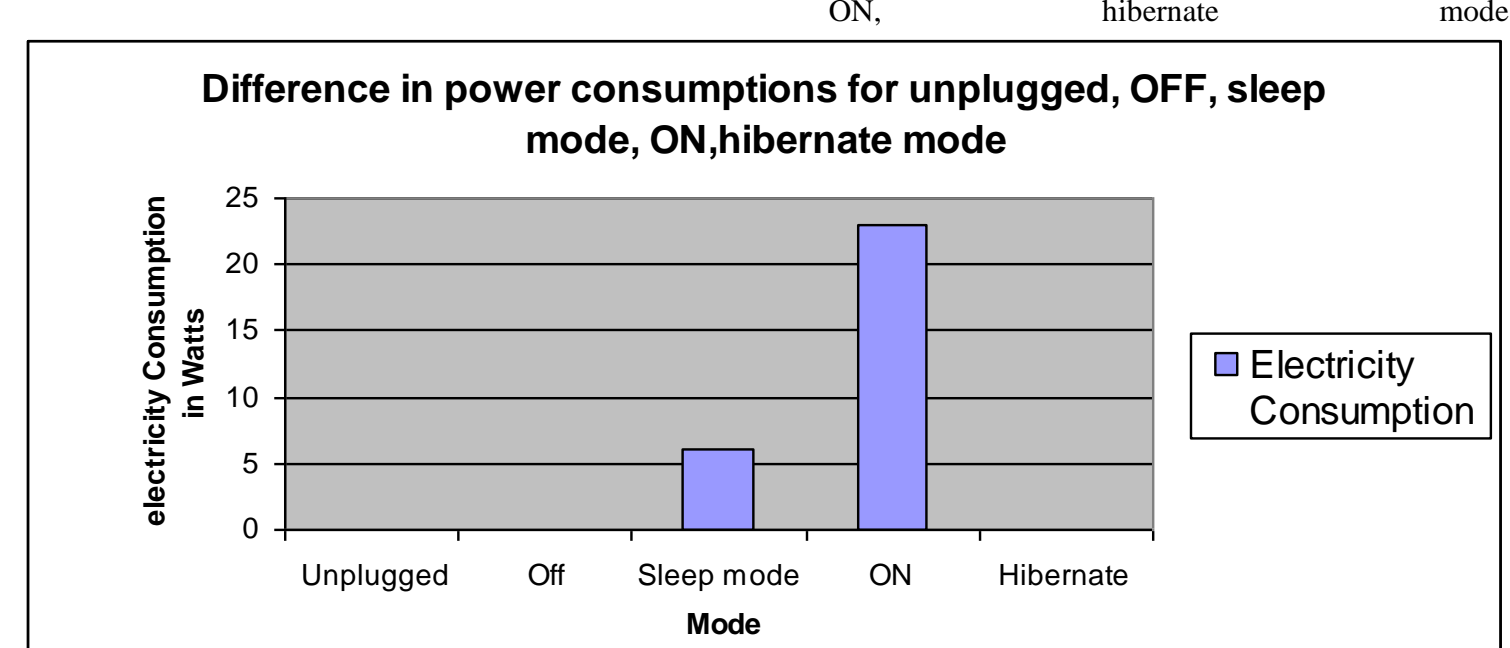

Figure 1: The desktop and laptop power consumption (in watts)

\subsection{Objectives of case study:-}

Reduction Of electricity consumption is performed at department level as yet and it is desirable to perform at college level. The objectives are

1) To identify electricity consumption at department level based on data collection and analysis.

2) Preventive measures to reduce the electricity consumption

3) Uses of advance technologies to achieve the goal of reduction in consumption of electricity.

\subsection{Methodology:-}

\subsection{1) Payback analysis}

is the length of time required recovering the cost of an investment. If the cash inflows occur at a uniform rate, it is the ratio of the amount initial investment over expected annual cash inflows.

Payback period $=$ initial investment/annual cash inflows

For calculating payback period department information is required. Hence, department survey is carried out for gathering the information of

laboratories, electrical consumption .

a)Total number of laboratories in department

b)Working and non-working hours of laboratories

c) Total number of CRT and LCD monitors in laboratories $=103$

d) Last four years (from 2009 to 2012) price list of CRT and LCD monitor

Table 1 shows, the CS and IT department having total 4 laboratories, out of which only 3 laboratories (Lab-1, Lab-2 and Lab-6) currently contain LCD monitors. There are total 103 computers, out of which 27 are CRT and 76 are LCD monitors. 
Table 1 : Computer labs in CS and IT department

\begin{tabular}{|c|c|c|c|c|}
\hline $\mathrm{A}^{\mathrm{p}}$ & Lab-1 & Lab-2 & Lab 4/5 & Lab 6 \\
\hline $\mathrm{B}^{\mathrm{q}}$ & 54 & 48 & 48 & 54 \\
\hline $\mathrm{C}^{\mathrm{r}}$ & $1(\mathrm{a})$ & $2(\mathrm{~b})$ & 2 & $1(\mathrm{c})$ \\
\hline $\mathrm{D}^{\mathrm{s}}$ & $\left(\mathrm{X}^{\mathrm{f}}\right) 28$ & 20 & 27 & 28 \\
\hline $\mathrm{CRT}^{\mathrm{LCD}}$ & 28 & 20 & 27 & 28 \\
\hline $\mathrm{X}^{\mathrm{f}}+\mathrm{Y}^{\mathrm{g}}$ & $\left(\mathrm{Y}^{\mathrm{g}}\right) 28$ & 20 & 0 & 28 \\
\hline
\end{tabular}

I] $\mathrm{p}=$ Name of lab $\mathrm{q}=$ Working hours per week $\mathrm{r}=$ Non-working hours per week $\mathrm{s}=$ Existing monitors for year 2009 $\mathrm{a}=$ Non-working hours of lab-1 $\mathrm{b}=$ Non-working hours of lab-2 $\mathrm{c}=$ Non-working hours of lab- 6 $a+b+c$ (non working hours of labs having LCD monitors $)=4$

$\mathrm{f}=$ total number of CRT monitors $=27$ $\mathrm{g}=$ total number of LCD monitors $=76$

II] Hours per week = total hours per week, (total 9 hours per day, total 6 days per week. Therefore total 54 hours per week)
III] Lab-1 =Laboratory 1, Lab-2=Laboratory 2, Lab$3=$ Laboratory 3

As per the voltage is considered CRT monitor consumes 80 Watts and LCD monitors consume 40 Watts. Table 2 shows if one CRT monitor is ON for 54 hours per week( which are non -working hours of Lab-1 ,Lab-2 and Lab-6) it consumes 2 units/week which cost 6 Rs. per week and 216 per year in contrast. If one LCD monitor is $\mathrm{ON}$ for the same hours/week it consumes only 1 unit/week which cost 3 Rs./weeks and $108 \mathrm{Rs}$./year which is exactly half as compare to CRT monitor.

Table 2 : Cost of electricity charges for single CRT and LCD monitor

\begin{tabular}{|c|c|c|c|c|}
\hline Monitors & Quantity & $\begin{array}{l}\text { Electricity } \\
\text { Consumption(units/week) }\end{array}$ & $\begin{array}{l}\text { Cost } \\
\text { electricity(Rs./week) }\end{array}$ & $\begin{array}{l}\text { Cost of electricity(Rs. Per } \\
\text { year) }\end{array}$ \\
\hline CRT & 1 & 2 & 6 & 216 \\
\hline LCD & 1 & 1 & 03 & 108 \\
\hline
\end{tabular}

I) Cost of electricity charges is 3 Rs. /unit (3 Rs.) $* 2$ (units) $=6$ Rs./week), unit=kwh

II) Rs. Indian Rupees

III) Total 9 hrs. Per day, Total 6 days per week, Total

36 weeks per year (16 weeks per semester, for 2 semester (for one year) total 32 weeks and 4 weeks for exam) One semester $=6$ months.

Table 3: Cost of electricity charges for 103 CRT and LCD monitors

\begin{tabular}{|l|l|l|l|l|}
\hline Monitors & Quantity & $\begin{array}{l}\text { Electricity } \\
\text { Consumption(units/week) }\end{array}$ & $\begin{array}{l}\text { Cost } \\
\text { electricity(Rs./week) }\end{array}$ & $\begin{array}{l}\text { Cost } \\
\text { electricity(Rs. Per } \\
\text { year) }\end{array}$ \\
\hline CRT & 103 & 1236 & 7416 & $2,66,976$ \\
\hline LCD & 103 & 618 & 1854 & 66,744 \\
\hline
\end{tabular}

Table 3 shows further calculations. If we utilize 103 CRT monitors for $54 \mathrm{hrs}$./week it costs 2,66,976 Rs./year and LCD monitor saves up to 2,00,232 Rs./year. So better option is to replace CRT with LCD monitors. Cost of LCD monitor is decreases year by year.
The market price of last four years (from 2009-2012) of LCD monitor is studied, the price found drastically decreasing as compared to previous year. If the same fact is considered it can be assumes that the rate will decrease in future also. This is shown in Table 4 and figure 2 given below

Table 4: Last four years (from 2009-2012) market price of LCD and CRT

\begin{tabular}{|c|c|c|}
\hline Year & $\begin{array}{c}\text { Cost of 18.5'(inches) LCD monitors } \\
\text { (Rs.) }\end{array}$ & $\begin{array}{c}\text { Cost of 18.5'’(inches) CRT monitors } \\
\text { (Rs.) }\end{array}$ \\
\hline 2005 & 14000 & 6,800 \\
\hline 2006 & 13,000 & 6,500 \\
\hline 2007 & 12,500 & 6,200 \\
\hline 2008 & 10,500 & 5,500 \\
\hline
\end{tabular}




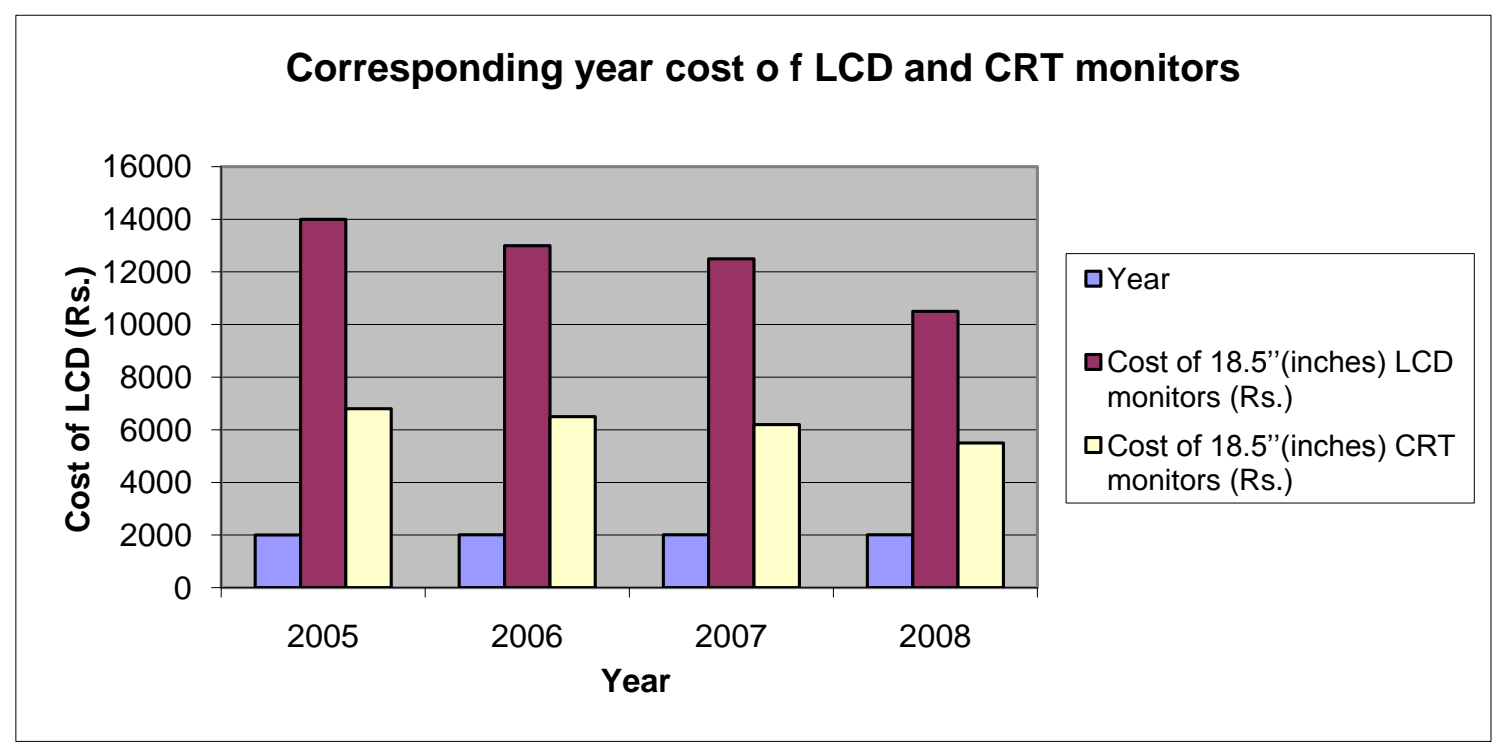

Figure 2 : Last 4 years (from 2005 to 2008) cost of LCD and CRT monitors

Table 5: Next 10 years ( from 2009 to 2018) data for LCD monitor and its cost

\begin{tabular}{|l|l|l|l|l|l|l|l|l|}
\hline Year & A & B & C & D & E & F & G & H \\
\hline 2008 & 1 & 0 & 0 & 7500 & 0 & 0 & 0 & 0 \\
\hline 2009 & 1 & 56 & 56 & 7000 & 392000 & 336 & 12096 & 36288 \\
\hline 2010 & 2 & 56 & 0 & 6500 & 0 & 336 & 12096 & 36288 \\
\hline 2011 & 2 & 56 & 0 & 6000 & 0 & 336 & 12096 & 36288 \\
\hline 2012 & 3 & 76 & 20 & 5500 & 110000 & 456 & 16416 & 49248 \\
\hline 2013 & 3 & 86 & 10 & 5000 & 50000 & 516 & 18576 & 55728 \\
\hline 2014 & 4 & 96 & 10 & 4500 & 45000 & 576 & 20736 & 62208 \\
\hline 2015 & 4 & 106 & 10 & 4000 & 40000 & 636 & 22896 & 68688 \\
\hline 2016 & 5 & 116 & 10 & 3500 & 35000 & 696 & 25056 & 75168 \\
\hline 2017 & 5 & 126 & 10 & 3000 & 30000 & 756 & 27216 & 81648 \\
\hline
\end{tabular}

Where
A- Electricity charges per unit(Rs.)
B- Existing LCD
C- New LCD
D- Cost per LCD monitor purchased

E- Total purchased cost(Rs.)

F- Electricity saved units per week

G- Electricity saved units per year

H- Cost of electricity saved Rs. Per year 


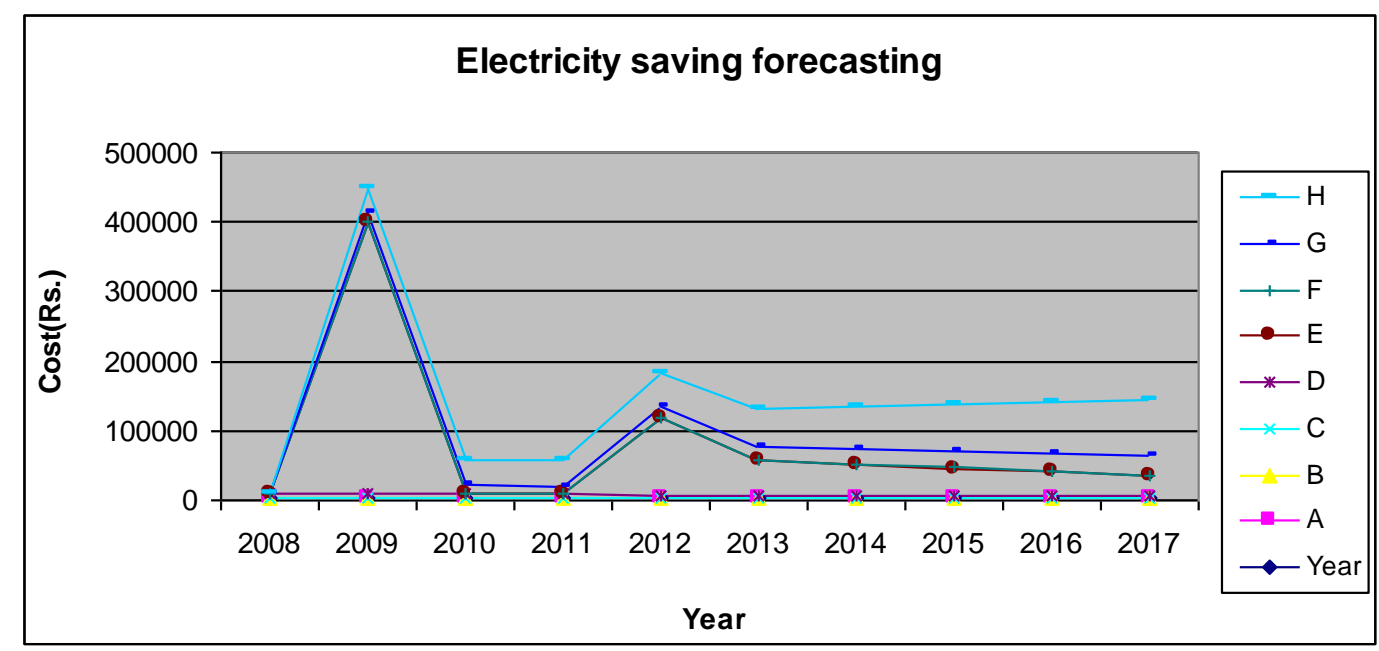

\subsection{Proposed Techniques:}

Figure 3 : Electricity Forecasting

1. Labs should be properly ventilated, not underground

2. Separate labs for low power computing requirement and high end computing.

3. Prevention from dust.

\subsection{Conclusion}

This paper was motivated by the rising cost of electricity in RS College. The conclusion of the case study illustrates the saving in electricity in case of LCD and CRT monitors. But other equipments like fans, tables in our laboratories can save energy much more than one can think. We had kept fans, tables, personal computers in OFF mode when work is over. Right now this is limited to computer science and IT department. In future we will apply these techniques to all other departments of our college.

The aim of this paper is to measure awareness levels of students and staff at RS College with regards to Green Computing. The research established that the awareness levels to electricity saving techniques for CS and IT department. By incorporating the green computing techniques discussed in this paper into RS College campus can have an immediate impact by reducing power consumption by computers and associated peripherals.

\subsection{References}

[1] Chakraborty P., Bhattacharyya D., Nargiza Y. and Bedajna N. (2009) International Journal of Grid and Distributed Compu-ting.

[2] Gingichashvili S. (2007) Green Computing.
[3] Tebbutt D., Atherton M. and Lock T. (2009) Green IT For Dummies, John Wiley \& Sons Ltd.

[4] Orfano F. (2009) How Computer manufacturers are using eco-friendly materials to reduce toxins.

[5] Stenzel P.L. (2004) Encyclopedia of Business, ISO 14000.

[6] Stenzel P.L. (2005) Sleeping Computers Help Keep Trent Green.

[7] Talebi M. and Way T. (2009) Methods, Metrics and Motivation for a Green Computer Science Program,

[8] Kruger H., Drevin L. and Steyn T. (2010) A vocabulary test to assess information security awareness.

[9] Steeves C., Abram A., Maurice G., Nonnecke B., Stevanus D. and Walker J. (2006) Campus Computing and the Environ-ment. Batlegang B. Journal of Information Systems and Communication

[10] Kanchan Khedikar,Komal Kumawat, Mahesh Mahant ,Rahul Hiremath (2010) International conference on emerging trends in computers, communication and IT 